\title{
BOUNDARY PATROLS AND INTERGROUP ENCOUNTERS IN WILD CHIMPANZEES
}

\author{
by
}

\author{
DAVID P. WATTS ${ }^{1,2)}$ and JOHN C. MITANI ${ }^{3,4,5)}$ \\ $\left({ }^{1}\right.$ Dept. of Anthropology, Yale University, P.O. Box 208277, New Haven, CT, USA \\ 06520-8277; ${ }^{3}$ Dept. Of Anthropology, The University of Michigan, 1020 LSA Bldg. Ann \\ Arbor, MI, USA 48109)
}

(Acc. 22-XI-2000)

\begin{abstract}
Summary
Chimpanzees are among the few mammals that engage in lethal coalitionary aggression between groups. Most attacks on neighbors occur when parties made up mostly of adult males patrol boundaries of their community's range. Patrols have time, energy, and opportunity costs, and entail some risks despite the tendency of males to attack only when they greatly outnumber their targets. These factors may lead to a collective action problem. Potential benefits include protection of community members, particularly infants; range expansion and increases in the amount and quality of food available; and incorporation of more females into the community. Males may not share these equally; for example, those able to obtain

2) E-mail address: david.watts@yale.edu

4) E-mail address:mitani@umich.edu

5) We thank The Uganda Wildlife Authority, Makerere University, and Drs. John Kasenene and Gilbert Isibirye-Basuta for permission to work at the Makerere University Biological Field Station. We thank Dr. Jeremiah Lwanga for his expert project management at Ngogo and his many contributions to research there. We are indebted to Godfrey Mbabazi, Adolph Magoba, Lawrence Ndagezi, and Alfred Tumusiime for invaluable assistance in the field and, in particular, for helping us to keep up with the chimpanzees on many of the boundary patrols described here. Richard Wrangham made valuable comments on ideas presented here, and his work on coalitionary aggression between groups inspired much of our thinking. We thank Jennifer Williams for sharing results of her doctoral research and Charlotte Hemelrijk for providing us with MATSQUAR. We thank Charles Snowdon and two anonymous reviewers, one of whom pointed out the possible relevance of costly signaling theory to boundary patrolling, for helpful comments on an earlier version of this paper. J. Mitani was supported by NSF Presidential Faculty Fellowship Award SBR-9253590, and D. Watts was supported by the L.S.B. Leakey Foundation, Primate Conservation, Inc., and Yale University.
\end{abstract}


large shares of matings may stand to gain most by participating in patrols and to lose most by refraining. Despite the attention that boundary patrolling has attracted, few relevant quantitative data are available. Here, we present detailed data on boundary patrolling and intergroup aggression in a chimpanzee community at Ngogo, Kibale National Park, Uganda, that is unusually large and has more males than any other known community. Males there patrolled much more often, and patrol parties were much larger on average, than at two other sites for which comparative data exist. Our findings support the argument that male participation varies along with variation in potential gains, in willingness to take risks, and in skill at handling these risks. Both the overall frequency with which individual males patrolled and their willingness to join patrols as others set off on them were positively associated with variation in mating success, in participation in hunts of red colobus monkeys, and in hunting success. Males patrolled relatively often with others with whom they associated often in general, with whom they often groomed, and with whom they formed coalitions in withincommunity agonism. This indicates that they were most willing to take risks associated with patrolling when with others they trusted to take the same risks.

Keywords: chimpanzees, intergroup aggression, boundary patrols, cooperation, collective action.

\section{Introduction}

Only a few mammalian species are known to engage in aggression in which coalitions from one social group make lethal attacks on members of neighboring groups (reviewed in Wrangham, 1999). These include several social carnivores (spotted hyaenas, Crocuta crocuta: Kruuk, 1972; lions, Panthera leo: Packer et al., 1990; Grinnell et al., 1995; wolves, Canis lupus: Mech et al., 1998; cheetahs, Acinonyx jubata: Caro \& Collins, 1986), as well as two omnivorous primates that commonly hunt mammals (chimpanzees, Pan troglodytes: Goodall et al., 1979; Goodall, 1986; Wrangham \& Peterson, 1996; Wrangham, 1999; humans, Homo sapiens: Manson \& Wrangham, 1991; Wrangham \& Peterson, 1996; Wrangham, 1999). Lethal intergroup aggression is associated with fission-fusion social systems in hyaenas, wolves, chimpanzees, and humans in small-scale societies. Lone individuals and those in small temporary associations (parties) are subject to attack by larger parties that encounter them in zones of range overlap or during territorial incursions (Goodall, 1986; Manson \& Wrangham, 1991; Keeley, 1996; Wrangham \& Peterson, 1996; Mech et al., 1998; Wrangham, 1999).

Chimpanzees live in fission-fusion communities, within which individuals form parties of varying size, composition, and duration (Nishida, 1968). Males are philopatric, whereas most adolescent females transfer from their 
natal communities into neighboring communities and some parous adult females transfer secondarily (Pusey, 1979). Males are antagonistic to those of other communities and are sometimes highly aggressive to extra-community females. In at least some populations, males regularly patrol the boundaries of their territories and sometimes make incursions into neighboring territories. Females and adolescent males sometimes accompany them. Males are wary and appear to be searching for neighbors or to be gathering information about their possible location. Responses to any neighbors they encounter vary from precipitous flight to stalking and sudden, intense attack (Goodall et al., 1979; Nishida et al., 1985; Goodall, 1986; Wrangham, 1999; Boesch $\&$ Boesch, 2000). Relative party size is probably the most important influence on variation in the course and outcome of intergroup encounters, and concerted attacks seem unlikely unless one side greatly outnumbers the other (Goodall, 1986; Manson \& Wrangham, 1991; Wrangham \& Peterson, 1996; Wrangham, 1999; Boesch \& Boesch, 2000). Lethal intergroup attacks other than infanticides, associated with patrols and incursions, are known from Gombe in Tanzania (Goodall, 1977, 1986; Goodall et al., 1979) and from Kibale in Uganda (Wrangham \& Peterson, 1996) and have been inferred in the Mahale Mountains National Park, Tanzania (Nishida et al., 1985).

Attackers probably face low risk of injury when they have overwhelming numerical superiority, especially because one or more of them typically try to immobilize the victim while others attack it (Goodall, 1986; Manson \& Wrangham, 1991; Wrangham \& Peterson, 1996; Wrangham, 1999). Still, attackers presumably face some risk of wounding, and males engaged in a patrol or incursion may meet equally strong or stronger antagonistic parties that retaliate (Boesch \& Boesch, 2000). Males rely on each other's support to minimize such risks. Patrols can last for hours and also have energy and opportunity costs. Possible compensating benefits can be subsumed under the 'imbalance of power' hypothesis, which proposes that successful attacks on members of neighboring communities result in general dominance over those communities (Manson \& Wrangham, 1991; Wrangham \& Peterson, 1996; Wrangham, 1999). In turn, this can lead to better access to food resources and, consequently, to higher female reproductive success (Williams, 1999; Wrangham, 1999); to more mating opportunities for males (Nishida et al., 1985; Wrangham, 1979, 1999); and to improved safety (Wrangham, 1999). 
Territorial defense in general, and boundary patrols in particular, may present collective action problems to male chimpanzees (Boehm, 1999; Wrangham, 1999). All males should benefit if effective patrolling and success in intergroup aggression leads to improved safety and, in principle, other benefits could also be distributed equitably. However, 'free riders' might then patrol less often than others and exploit their willingness to assume associated costs (Boehm, 1999; Wrangham, 1999; cf. Grinnell et al., 1995; Heinsohn \& Packer, 1995). Cheating may not be difficult in a fission-fusion society, especially one with many males, because individuals are often not together and cannot have perfect information about others' behavior. One way to cheat would be to avoid boundary areas, and thus to be absent at the start of many patrols (although patrols sometimes start well within boundaries; Watts \& Mitani, 2000). Another would be for a male to refrain when he has an opportunity to join a patrol - that is, to stay behind when others he is with set off. In that case, others have information about his behavior and may punish him, withhold cooperation from him in the future, or otherwise alter their behavior in response.

However, not all males would necessarily benefit equally from increased female reproductive rates, improved infant survival, or the inclusion of more females in their community. For example, if high rank confers reproductive advantages, currently high-ranking males may be particularly inclined to participate in patrols because they have relatively many current offspring. Males who can expect to attain and sustain high rank may also patrol often because their expected number of future offspring is relatively high. By the same token, males with low current reproductive success and poor future prospects have less to lose by refraining from patrols. The extent to which individual males participate in community defense and inter-community aggression may depend on how much they stand to lose if neighbors make successful incursions, and how much they stand to gain in the future if they can expand their territory at the expense of neighbors. Males who patrol relatively infrequently may not be cheating.

Patrols have time, energy, and opportunity costs, and they entail some risk of injury in aggressive encounters with neighbors. Males who patrol often may be advertising their ability and willingness to take risks, in situations in which risk minimization depends on cooperation. That is, patrolling may be a form of costly signaling (Zahavi, 1975; Grafen, 1990). One possibility is that patrolling advertises a male's quality as a mate, but this could only work 
if females receive information about his participation. Another possibility is that it gives other males information about his quality as an ally in within-community competition. In turn, information about the willingness of males to cooperate in within-community competition and to invest in relationships that involve cooperation, e.g. by providing grooming, could influence decisions about whether to start a patrol, depending on which males are actually present. If a community has enough males that they have multiple options to form parties large enough for low-risk patrols, individuals may be most inclined to join patrols if other participants are reliably cooperative social partners.

Behavior during hunts of red colobus monkeys (Piliocolobus badius), another activity that chimpanzees undertake in groups and in which they risk injury (Goodall, 1986; Boesch \& Boesch, 1989, 2000; Boesch, 1994; Stanford et al., 1994; Stanford, 1998), also gives information about male willingness to take risks and to cooperate and about fighting skills. Cooperation can increase hunting success and presumably decreases the risks that individual hunters take (Boesch \& Boesch, 1989, 2000; Boesch, 1994). The same motivational system may underlie attacks on conspecifics from other groups and hunting of heterospecifics (Eibl-Eibesfeldt, 1979; Goodall, 1986; Wrangham \& Peterson, 1996; Wrangham, 1999). In any case, males skilled at hunting may also be particularly inclined to engage in patrols, and others may be most inclined to go on patrols when good hunters are present.

Intergroup aggression in chimpanzees has attracted much discussion, but published data on the frequency of boundary patrols and inter-community encounters and on individual variation in participation in these activities are still scarce (but see Boesch \& Boesch, 2000). We add to this record here by describing boundary patrols and inter-community encounters for a recently habituated and unusually large chimpanzee community at Ngogo, Kibale National Park, Uganda. We have four main objectives. First, we describe the frequency of patrolling, the size and composition of patrols, and variation in the location of patrol routes. Second, we analyze individual variation in the overall frequency with which males participated in patrols and examine several hypotheses that may account for this variation. We use data on male dominance rank and mating success for a preliminary test of the hypothesis that individual participation in patrols correlated positively with variation in expected benefits from success in inter-community antagonism. We use data on participation in hunts and hunting success to evaluate whether these were 
positively related to willingness to patrol. We also use data on grooming and coalition formation to test the hypothesis that males tended to patrol jointly with others with whom they maintained strong affiliative ties and cooperated in within-community antagonism. Third, we consider the possibility that some males cheated by refraining from joining patrols when they had the opportunity to do so. Finally, we compare our data to those available from chimpanzee communities at Gombe (Goodall, 1986) and Tai (Boesch \& Boesch, 2000), and examine variation in patrol frequency and composition in light of demographic variation.

\section{Methods}

\section{Study site and subjects}

We made our observations in the Ngogo study area in Kibale National Park, Uganda. The study area comprises a mix of mature, mid-altitude rainforest, secondary forest, swamp forest, and grasslands dominated by Pennisetum purpureum (Struhsaker, 1997). Ghiglieri (1984) first studied the chimpanzee community at Ngogo in 1976-1978 and in 1981. Research and habituation efforts resumed in 1991, and we started work there in 1993. Observations of the Ngogo chimpanzee community have been continuous and habituation efforts intensive since 1995. By the time of the observations reported here, all males could be approached to within 5 to $10 \mathrm{~m}$ on the ground. The Ngogo chimpanzee community is the largest described thus far (Watts, 1998, 2000a, b; Mitani et al., 1999; Mitani \& Watts, 1999; Pepper et al., 1999; Mitani et al., 2000; Watts \& Mitani, in press a, b). Its exact composition is uncertain because not all females are well habituated or individually recognizable. However, it contained 24 adult males, 15 adolescent males, and about 47 or more adult females, nine adolescent females, and 49 juveniles and infants, for a total of at least 144 members, as of mid-1999. The numbers of males far exceed means of 7.3 adults and 3.5 adolescents for a sample of 11 chimpanzee communities from throughout the species range (Wrangham, 2000).

We have followed Ngogo chimpanzees over about $35 \mathrm{~km}^{2}$ (Fig. 1) since 1993 and have a good sense of the area within which males typically stay during normal foraging. This area abuts the range of the habituated Kanyanchu community to the south and southwest, although we do not know the exact extent of the shared boundary and of range overlap. It abuts the range of at least one unhabituated community to the north and, probably, northeast. We have been with Ngogo chimpanzees when they encountered neighbors in areas near the eastern and southeastern edges of their range, but do not know if these belonged to the northern community or to another unhabituated community. We also have recorded encounters to the west and northwest with what may be a community distinct from those just noted. We divided the perimeter of the Ngogo community's range into eight straight-line sectors, each about 2 $\mathrm{km}$, in order to quantify how often they patrolled in certain areas (Fig. 1). This division is partly arbitrary, but some sector endpoints correspond roughly to geographic features relevant to patrol routes. The trail that passes between Ngogo and the field station at Kanyawara forms the western endpoint of Sector 1; the chimpanzees often use this trail as a jumping-off point to patrol to the east and northeast. Similarly, they often cross the road in to Ngogo camp 


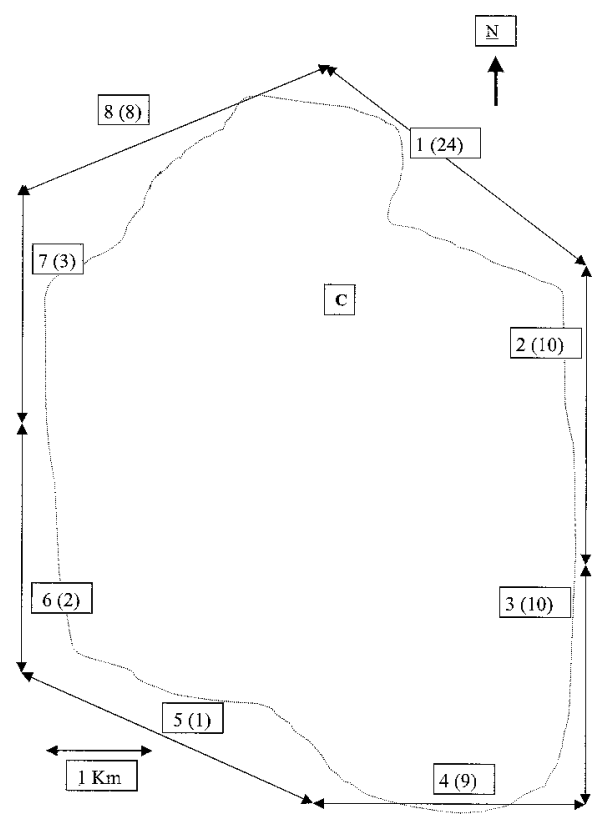

Fig. 1. Home range of the Ngogo chimpanzee community. Dashed line gives approximate territorial boundaries; solid lines show the eight sectors that we identified in order to estimate the frequency with which males patrolled certain parts of the perimeter. The first number in each box is the sector number. The value in parentheses gives the number of times that patrols reached a given sector (these sum to more than 52 because the chimpanzees could reach more than one sector on a given patrol). $\mathrm{C}=$ location of research camp.

at about the north-south coordinate that demarcates Sector 2 from Sector 3, and sometimes swing either northeast or southeast to patrol from there. A trail that goes south from the Ngogo trail grid system, initially along the Kanyanchu stream, and that eventually intersects the trail grid system in the Kanyanchu study area, demarcates Sector 4 from Sector 5.

\section{Data collection and identification of patrols}

Males sometimes move long distances near or along known boundaries in a highly distinctive fashion that fits descriptions of boundary patrols from Gombe (Goodall, 1977, 1986) and Tai (Boesch \& Boesch, 2000). They travel in file formation, with little distance between individuals, are uncharacteristically silent, and usually do not feed. They often stop and sit or stand in a tight cluster, intensely vigilant, apparently to look and listen for other chimpanzees, and they sometimes stop to inspect chimpanzee night nests or areas where chimpanzees have been eating fruit. Sometimes they sniff the ground as if they can smell chimpanzee urine. They remain highly vigilant until they have moved well back towards the center of their range.

We began to follow males on patrols in 1996 and have since noted that these occur at high frequency. Most of the data reported here come from January to June, 1998, and October, 
1998 through August, 1999, when one or both of us was at Ngogo. During these times, we rarely lost contact with parties that had more than two to three males once we had found them and thus were highly likely to see patrols when they occurred. During patrols, we note the identity of all participants and the route that they follow, collect general data on behavior, and make detailed observations of responses to signs of other chimpanzees and of interactions between the patrollers and conspecifics encountered. We collect similar data when we are with Ngogo chimpanzees engaged in normal foraging or other, non-patrol activities and we hear calls from areas near boundaries or observe encounters with other chimpanzees. We are not always certain of the community to which callers belong, but we have documented several encounters with the habituated Kanyanchu community.

Wrangham (1999) distinguished between patrols along boundaries and deep incursions, during which members of one community travel relatively far into a neighboring territory. One indication that Ngogo chimpanzees make deep incursions is that they sometimes display loudly on their return to an area well within their range ( $c f$. Wrangham, 1999). However, we do not try to distinguish these from patrols here because we know too little about range overlap with neighboring communities.

\section{Data analysis}

We used data from 1998 and 1999 to estimate the rate of patrolling. We calculated this rate by dividing the number of observed patrols by the number of days on which we were with chimpanzees for at least six hours; this makes our measure comparable to those of Goodall (1986) for Gombe and of Boesch \& Boesch (2000) for Tai. This is a conservative estimate, because we might have missed patrols on days when we saw none or only a few of the community's adult males.

Counting how often a male went on patrols is one measure of his engagement in such collective actions. To test the hypothesis that adult males patrolled equally often, we first calculated the total number of male 'patrol days' $(N=489)$. This was the number of times that individual males went on patrols, summed across all males. Multiplying mean patrol size by the number of patrols gives the same result. Parties that went on patrols were usually large (see below). Males we saw relatively infrequently tended to be in large male parties least often. It seemed unlikely that they were under-represented in our sample of patrols as a result, because they were unlikely to have been patrolling, alone or in small parties, when we were with large parties of males and they were not present. Still, we needed to consider the possibility that the number of times we saw individuals on patrols depended simply on how often we saw them at all. We thus counted the number of days on which we saw each male and calculated what percentage of total male observation days this represented. We then multiplied 489 by these percentages to calculate the expected numbers of times we should have seen each male on patrols if this depended only on how often we saw him. We also divided 489 by the number of males in the community to obtain an expected value of 20.4 patrols per male, under the assumption that our observations were an unbiased sample of patrols. We compared observed and expected values with chi-square tests.

Counting the number of patrols does not necessarily indicate how willing males were to participate when they had an opportunity to do so (or, conversely, how often they exploited the willingness of others). As a measure of willingness, we calculated what proportion of times each male went along when other males he had been with did a patrol. We considered males to have refrained either when they did not go at all, or when they went a short distance, but then 
dropped out while others continued. These data complement those obtainable from playbacks, which simulate immediate external threats (Grinnell et al., 1995; Heinsohn \& Packer, 1996), because patrols start in the absence such threats. We examined the null hypothesis that the proportion of times that males refrained did not vary significantly across individuals with a chi-square test.

We also counted how often each adolescent male went on patrols, but we probably missed or misidentified some adolescents early in the study because most were less well habituated than the adults and we were less familiar with them. We therefore offer only a preliminary analysis of their participation in patrols. All results given below pertain to adult males only, unless we specify that they pertain to adolescents.

We assessed male dominance rank on the basis of decided agonistic interactions during the 1998-1999 study periods ( $c f$. Watts, 1998). We assigned equal rank to some males between whom we saw no decided interactions. Several males rose or fell in rank during this period, and we used their mean ranks in analyses below. There was a strong positive correlation between the frequency with which males copulated with parous estrous females and male dominance rank, but also considerable residual variation (Watts, unpubl. data). This raises the possibility that (1) male rank and reproductive success are also positively correlated, but that (2) a few males have relatively high or low fertilization success independently of rank. We do not currently have paternity data with which to test these hypotheses. Relatively high current success at mating and potentially siring offspring should give males a high incentive to defend their community boundaries against intruders and to try to expand their territory. To investigate whether rank and mating success influenced the inclination of males to participate in patrols, we regressed patrol participation on male rank; on male mating success, defined as the mean percentage of copulations that a male obtained with each of five parous females; and on the residuals from the regression of mating success on rank, a rank-independent measure of mating success.

To examine the relationship between male hunting behavior and participation in patrols, we calculated the number of red colobus hunts at which each male was present and the mean number of kills each male made per hunt ( $N=82$ hunts total). We then analyzed the relationships between these measures and patrol participation. A male was 'present' if we saw him while prey pursuit was underway. For various reasons (e.g. many chimpanzees are present at most hunts, they often spread over large areas, and they can quickly switch from watching action in the canopy to pursuing prey), we cannot accurately record how often each individual actually pursues prey, and we consider all males present to be potential hunters (Mitani \& Watts, 1999, Watts \& Mitani, in press a, b). Most hunts at Ngogo are of red colobus; including data from hunts of other monkey species does not change the results.

We used MATSQUAR (Hemelrijk, 1990a) to test for associations between the number of times each male dyad participated in a patrol together and the following variables: grooming between males, coalitions, and joint presence at hunts. We used data on the total duration of grooming per dyad ( $c f$. Watts, 2000a). Two males formed a 'coalition' when they jointly directed aggression at one or more third parties; we included only coalitions directed at other adult males. MATSQUAR is a matrix permutation program that calculates several indices of association between variables from observed dyadic values, then randomly permutes row and column values to generate sampling distributions against which to test the significance of test statistics derived from the original data matrix. It thus avoids problems associated with the non-independence of dyads and with the fact that sampling distributions for dyadic values are unknown (ibid.). We also used MATSQUAR Partial (Hemelrijk, 1990b) to control for the 
number of patrols in which each male participated and then to calculate the correlations of how often males patrolled together with the following variables: how much they groomed with each other, how often they formed coalitions, and how often they hunted together. Grooming data come from focal samples and represent the total duration of grooming (Watts, $2000 \mathrm{a}, \mathrm{b})$. We used $K_{\mathrm{r}}$ tests, which give a multivariate version of Kendall's S statistic $\left(\tau_{\mathrm{Kr}}\right)$ corrected for samples sizes and ties, and used 2,000 permutations for each test. Data and hypothesis matrices were symmetrical.

\section{Results}

\section{Patrol rate, size and composition}

We followed chimpanzees on 52 boundary patrols. Five of these took place during two, three-month long field seasons in 1996 and 1997. The others occurred during fieldwork in 1998 and 1999 and give an estimated rate of one patrol per 9.7 days, or 0.72 per week. This is considerably higher than values for the Kasakela community at Gombe during 1977 through 1982 (0.30 patrols per week: Goodall, 1986) and for the northern community at Tai (0.3 patrols per week: Boesch \& Boesch, 2000). Patrol rates have varied over time at Gombe, however, and patrols were most common during the period when Kasakela males repeatedly attacked those in the Kahama community (Goodall, 1986).

Patrols at Ngogo included three to 27 members, with a mean of 13.0 (SD $=5.6$ ). Patrols were almost exclusively male activities, and most participants were adult males. The mean number of adult male participants was 9.4 ( $\mathrm{SD}=3.8$, range 3-19), and the mean number of adolescent males was $3.6(\mathrm{SD}=2.8$, range $=0-10)$. One unusually large adult female who does not undergo menstrual cycles twice joined males on patrols; this female accompanied adult males unusually often in general. One adolescent female also twice joined males on patrols; both times, she was in estrus. Otherwise, females did not participate in patrols. At Tai, patrols were smaller on average ( $\bar{x}=8.2$ members; $N=38$ patrols; Boesch \& Boesch, 2000) and contained considerably fewer males $(\bar{x}=5.2)$. However, proportionately more of the community's males took part in each patrol at Tai (72\%) than at Ngogo (39.2\%). Also, adult females joined $57 \%$ of patrols at Tai, and a mean of 2.2 females participated in each patrol. Goodall (1986) does not provide data on patrol composition at Gombe. However, the Kasakela community contained means of 5.6 adult and 1.3 'late' adolescent males during 1977-1982, so 
patrols necessarily contained fewer individuals from each of these classes than the means at Ngogo, although Gombe patrols might have contained proportionately more of the community's males, on average, than Ngogo patrols did.

Two non-mutually exclusive factors could explain why patrols were more common at Ngogo than at Tai or Gombe. First, individuals at Ngogo might have been more inclined to go on patrols because they had more partners, which should have decreased their risks. Alternatively, Ngogo males might have participated in patrols at rates equal to or even lower than those at the other sites, but patrols were more common simply because more males were there to participate. Both possibilities find some support. Tai data show that males are not inclined to patrol when associated risks are particularly high (Boesch \& Boesch, 2000). The rate of patrolling at Tai dropped sharply when the number of males declined to only four. Small patrolling parties were also much less likely than large patrolling parties to attack neighbors on encounter, and they usually avoided neighbors. The mean annual number of patrols per capita was higher at Ngogo (14.2) than at Tai (about 10; estimated from data in Boesch \& Boesch, 2000), suggesting that Ngogo males were more inclined to go on patrol. However, males at Ngogo seemed no more inclined on average to go on patrols than males at Gombe, where the mean per capita annual number of patrols was 14.4 (calculated from data in Goodall, 1986).

\section{Patrol locations}

Most patrols occurred near boundaries to the northeast, east, and southeast (Fig. 1). We often followed Ngogo chimpanzees to the west in 1997 and early 1998, but by mid-1998 most males rarely traveled near or across apparent boundaries to the west, and neared those to the southwest and northwest much less often than more easterly boundaries. They might have shifted their activities partly to avoid the Kanyanchu community, which is also unusually large, in the south and southwest. However, most large fruit crops on which they fed in the second half of 1998 and in 1999 were in the central and eastern parts of their range.

Ngogo chimpanzees patrolled Sector 1 (Fig. 1) 20 times during an 11month interval during 1998-1999. Intervals between patrols ranged from one to 60 days during this time, with a median of nine days. Patrolling in this 
sector was particularly intense in June through August, 1999, with 13 patrols in 92 days. Patrols reached Sector 2 (Fig. 1) seven times, with a median interval of 17 days, in 1999, and twice reached this area within intervals of a week or less. The median interval between patrols was 27 days for Sector $3(N=7)$ in 1998 to 1999 . Patrols reached Sector 4 (Fig. 1) at intervals of $3,4,5,7$, and 11 days, but the chimpanzees also went 158 days without a known patrol to this sector.

\section{Encounters with members of other communities}

Ngogo chimpanzees heard and/or met neighbors on 19 of 52 patrols and on seven additional occasions while they were foraging. Most contact with neighbors was auditory only (Table 1). Responses to vocalizations from neighbors ranged from counter-calling, with or without approaches, to silent flight, to attacks (Table 1). Four times patrol members fled after hearing pant hoots from adult males or otherwise realizing that they were near members of a neighboring community, and twice subsequent calls from opposing males indicated that they pursued the Ngogo patrollers for some distance. Patrol members fled three times on meeting parties from the community to the north, and once fled from calls in Sector 7, to the west. On one of these occasions, the patrol included only three adult and three adolescent males; these males heard pant hoots from a party of northern males, but sat and waited, only to flee back towards the center of their own range when the northern males attacked them 10 minutes later.

Ngogo males attacked presumed neighbors during seven patrols; this included two separate attacks during one patrol (Table 1; Watts \& Mitani, 2000). They had heard vocalizations before six of these attacks, and apparently heard the strangers moving or feeding before the other two. Five attacks led to physical aggression; in the other three, males displayed at or under the strangers and chased several, but did not make contact (Table 2). All attacks were on parties that included females with or without accompanying immatures, but no adult or adolescent males (Table 2). Two attacks on solitary lactating females led to infanticides (Watts \& Mitani, 2000).

Sometimes when patrol members heard or met other chimpanzees they approached and even attacked them; sometimes, they avoided or fled from them (Table 1). Patrolling parties that approached or attacked tended to be larger and to include more adult males than patrolling parties that fled or 
TABLE 1. Outcome of encounters between Ngogo patrols and members of neighboring communities

Outcome category

Hear Meet

Patrol size:

Adults Adol

1) Avoid

2) Approach silently, no meeting

3

11

4.3

3) Counter-call, no approach;

2

11.5

4.5

leave or avoid

4) Counter-call, approach, no meeting;

2

10.5

2.5 others avoid

5) Wait, then flee

6) Flee

7) Attack

3

$1^{\mathrm{a}}$

3

3

1

10.5

4.5

Victims:

11.3

Solitary adult female: $1 *$

Solitary adult female/infant: $2(2 *)$

Adult females/immatures: $3(1 *)$

$?^{\mathrm{c}}: 1^{*}$

$N=19$ encounters. Hear $=$ auditory contact only. Contact $=$ contact aggression during attack. Victims $=$ targets of attacks; those with * received contact aggression. 'Patrol size' gives mean number of adult and adolescent ('Adol') males for samples larger than one.

${ }^{a}$ Patrol members had heard calls from neighbors but waited; neighbors then attacked;

${ }^{b}$ Patrol members had heard vocalizations before at least four attacks;

${ }^{\mathrm{c}}$ Observer heard sound of blows but could not see victim(s) because of dense vegetation (Watts \& Mitani, 2000).

avoided other chimpanzees (Table 1). The median number of participants when patrols attacked or approached was 16; the median number of adult males was 13, and of adolescent males 4. Patrols that fled or avoided others had a median of 11 members, with medians of 9.5 adult and 3 adolescent males. However, these differences were not significant (Mann-Whitney $U$ tests: $U=98.5, m, N=9,10$, NS, for total patrol size; $U=97.5$, $m, N=9,10, \mathrm{NS}$, for number of adult males). The smallest patrols that encountered others fled or avoided them. For example, a patrol that included only three adult and four adolescent males fled from a party from the northern community that included at least several adult males, who briefly chased them. Outcomes of encounters depend on the size and composition of the parties encountered, not just on the size of the patrol. For example, the largest patrol, which also had the most adult males (19 adult and 8 adolescent males) fled on hearing calls from an apparently large party to the west; these might 
TABLE 2. Context and outcome of inter-community encounters that occurred while Ngogo chimpanzees were foraging

\begin{tabular}{|c|c|c|c|c|c|c|c|c|c|c|}
\hline \multirow[t]{2}{*}{ Date } & \multirow{2}{*}{$\begin{array}{l}\text { Map } \\
\text { sector }\end{array}$} & \multirow[t]{2}{*}{ ID } & \multirow[t]{2}{*}{ Meet } & \multicolumn{6}{|c|}{ Composition: } & \multirow[t]{2}{*}{ Outcome: } \\
\hline & & & & $\mathrm{AM}$ & $\mathrm{AdM}$ & $\mathrm{EF}$ & $\mathrm{AF}$ & $\mathrm{AdF}$ & Total & \\
\hline $11 / 25 / 95$ & 7 & $?$ & No & 15 & 9 & 0 & 0 & 0 & 24 & $\begin{array}{l}\text { Counter-call, wait; } \\
\text { leave area } \\
\text { after } 0.5 \mathrm{~h}\end{array}$ \\
\hline $12 / 29 / 98$ & 4 & Kanyanchu & Yes & 6 & 10 & 1 & 5 & 0 & 34 & $\begin{array}{l}\text { Attack; counter- } \\
\text { attack and } \\
\text { counter-calling } \\
\text { both then } \\
\text { leave area }\end{array}$ \\
\hline $1 / 21 / 99$ & 4 & Kanyanchu & Yes & 21 & 12 & 3 & 4 & 0 & 43 & $\begin{array}{l}\text { Attack; others } \\
\text { display and } \\
\text { call, then flee }\end{array}$ \\
\hline $1 / 25 / 99$ & 5 & Kanyanchu & No & 9 & 4 & 0 & 0 & 0 & 13 & Call/Flee \\
\hline $2 / 12 / 99$ & 5 & Kanyanchu & No & 4 & 1 & 0 & 2 & 0 & 7 & Silent/Avoid \\
\hline 2/24/99 & 5 & Kanyanchu & No & 3 & 2 & 0 & 0 & 0 & 5 & Silent/Avoid \\
\hline $2 / 26 / 99$ & $2 / 3$ & $?$ & Yes? & 5 & 0 & 0 & 0 & 0 & 5 & $\begin{array}{l}\text { Charge/Display, } \\
\text { then leave area }\end{array}$ \\
\hline
\end{tabular}

ID = identity of neighboring community, if known. Meet: Yes = visual contact; No = auditory contact only. Composition: $\mathrm{AM}=$ adult male; $\mathrm{AdM}=$ adolescent male; $\mathrm{EF}=$ estrous female; $\mathrm{AF}=$ other adult females; $\mathrm{AdF}=$ adolescent female; $\mathrm{J} / \mathrm{I}=$ juvenile or infant.

have come from the Kanyanchu community, which also has at least 20 adult males. The third largest patrol (14 adult and 10 adolescent males) also fled after hearing neighbors. The second infanticidal attack was by a party that was smaller than the mean (12 members) and included fewer adult males (eight) than on average, but the female whom they attacked was alone (Watts \& Mitani, 2000).

A moderately large foraging party of Ngogo chimpanzees fled when they heard calls from chimpanzees, presumably from Kanyanchu, in Sector 5. They counter-called as they fled (Table 2). Two other, small foraging parties silently avoided chimpanzees presumed to be from Kanyanchu after hearing calls in the same area (Table 2). Large foraging parties met Kanyanchu chimpanzees twice in Sector 4 and charged at them, although without any known physical contact between individuals (Table 2). On one of these occasions, Kanyanchu chimpanzees fled after some counter-calling and counter-charging, and the Ngogo chimpanzees remained in the area. In the second encounter, both parties left the area after counter-calling and counter- 
charging. In another encounter, 16 adult and eight adolescent males from Ngogo approached and counter-called with a party that included multiple adult males after hearing calls from Sector 7, but did not meet them (Table 2). After 0.5 hours, the Ngogo males travelled more than $1 \mathrm{~km}$ from the area towards the center of their range, although not unusually quickly.

\section{Variation in male participation}

Males who were present during all observation periods participated in a mean of 19.8 patrols ( $\mathrm{SD}=7.5$, range 4-33; Fig. 2). The distribution of patrol frequencies differed significantly from that expected under the null hypothesis that males patrolled in direct proportion to the number of days on which we observed them $\left(\chi^{2}=53.13\right.$, df $\left.=23, p<0.001\right)$. We therefore took our observed values as reliable estimates of how often individual males went on patrols. The absolute frequencies with which males went on patrols differed significantly from those expected under the null hypothesis of equal participation $\left(\chi^{2}=65.50\right.$, df $=23, p<0.001$; Fig. 2). The oldest male joined only four patrols and should perhaps not be included in the analysis, but patrol participation still varied significantly with him excluded $\left(\chi^{2}=52.50, \mathrm{df}=22, p<0.001\right)$.

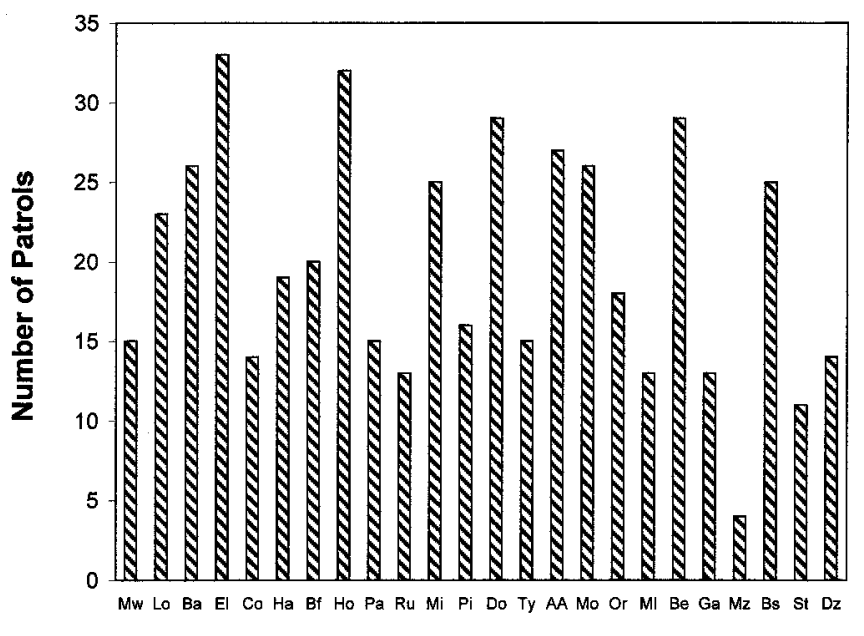

Male

Fig. 2. Number of patrols in which individual adult males participated. Males are ordered from left to right along the ordinate by dominance rank. 
Frequency of patrolling was independent of male dominance rank ( $r=$ 0.14 , df $=23$, NS). The male who held alpha rank during all study periods until April, 1999, patrolled relatively infrequently (15 times; Fig. 2). Several other high-ranking males were also not among the most active patrollers, while several middle-to-low ranking males were. Patrol frequency was significantly and positively correlated with the mean percentage of copulations that individual males achieved with parous females $(r=0.41$, df $=23, p=0.04)$. However, patrol frequency was not significantly correlated with rank-independent mating success $(r=0.29$, $\mathrm{df}=23, p=0.17)$.

Hunting behavior and patrolling were strongly associated with each other. Males who often joined hunts of red colobus also often joined patrols $(r=$ $0.66, p<0.001)$. Those who killed relatively many red colobus per hunt participated in patrols relatively often $(r=0.43, p<0.05)$. These measures of hunting behavior were also positively and significantly correlated with each other. Multiple regression models in which either number of red colobus hunts or number of kills per hunt was entered as a first independent variable, with overall mating success as a second predictor variable, failed to explain more of the variance in patrol frequency than participation in hunts or kills per hunt alone explained.

\section{Joint participation in patrols}

Results of $K_{\mathrm{r}}$ tests show that the frequency with which male dyads patrolled together was positively correlated with the amount of time that they groomed with each other $\left(K_{\mathrm{r}}=1,362, \tau_{\mathrm{Kr}}=0.24, N=24, p=0.0001\right)$. The frequency of joint participation in patrols was also positively correlated with the frequency of coalition formation between males $\left(K_{\mathrm{r}}=974, \tau_{\mathrm{Kr}}=0.22\right.$, $N=24, p=0.001)$ and with the frequency of joint participation in red colobus hunts $\left(K_{\mathrm{r}}=2,306, \tau_{\mathrm{Kr}}=0.41, N=24, p=0.0005\right)$.

The number of times that males were together on patrols also increased with the number of patrols they joined $\left(K_{\mathrm{r}}=3,942, \tau_{\mathrm{Kr}}=0.69, p=\right.$ 0.0005). This raises the possibility that correlations of joint participation with social variables might have been byproducts of a correlation between the number of times that males were together on patrols and the number of times that they went on patrols at all. However, matrix partial correlation tests that controlled for overall participation in patrols showed this not to be the case: all social variables remained significantly correlated with the frequency of joint patrols (grooming: $\tau_{\mathrm{xy} . \mathrm{z}}=0.10, p=0.049$; coalition formation: $\tau_{\mathrm{xy} . \mathrm{z}}=0.17, p=0.046$; hunting together: $\left.\tau_{\mathrm{xy} . \mathrm{z}}=0.12, p=0.047\right)$. 
Refraining from patrols

On average, males had 25.5 patrol opportunities $(\mathrm{SD}=7.2$, range $=8-37$; Fig. 3) and joined $77.3 \%$ of these patrols $(S D=12.7 \%$, range $=50.0$ 97.0\%). Variation in the proportion of times that males joined patrols when they had opportunities was not significant overall $\left(\chi^{2}=11.20\right.$, df $\left.=22, \mathrm{NS}\right)$ and was independent of dominance rank $\left(F_{1,22}=1.35, r^{2}=0.02\right.$, NS), but some individual cases were notable. The oldest male, MZ, was present at the start of only eight patrols and refrained proportionately most often (50\%). Another old male, RU, was present 25 times but refrained 12 times (48\%), the second highest value. Long-time alpha male MW refrained on 10 of 25 occasions $(40 \%)$, the third highest proportion. In contrast, males EL and HO joined the highest and second highest number of patrols, and refrained from the lowest and second-lowest proportions $(3.0 \%$ and $8.6 \%$ of opportunities, respectively). Males BF, PI, TY (Fig. 3) also joined patrols at most opportunities, although they had fewer opportunities than many other males and were thus not among the most frequent participants.

Like overall patrol participation, willingness to take opportunities to patrol was positively related to the number of red colobus hunts in which males participated $\left(F_{1,22}=5.29, r^{2}=0.16, p=0.031\right)$ and to red colobus hunting

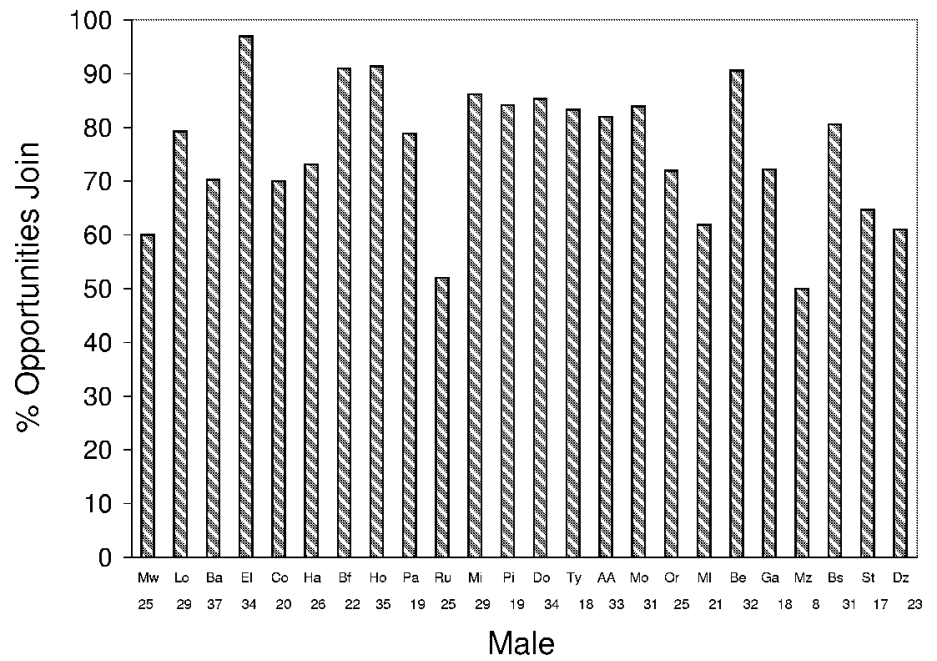

Fig. 3. Proportion of times that males joined patrols when they had the opportunity to do. Males are ordered from left to right along the ordinate by dominance rank. Number below a given column is the number of opportunities for that male. 
success $\left(F_{1,22}=7.59, r^{2}=0.22, p=0.012\right)$. The proportion of times that males joined patrols when given the opportunity was independent of mating success $\left(F_{1,22}=0.96, r^{2}=0.04, \mathrm{NS}\right)$. However, it was positively associated with residual mating success $\left(F_{1,22}=4.76, r^{2}=0.14, p=0.040\right)$.

\section{Patrolling by adolescent males}

Judging from our sample of firmly identified individuals, adolescent male participation in patrols varied widely (Fig. 4). Individual adolescents participated in a mean of 12.7 patrols $(\mathrm{SD}=9.1$, range $=1-28)$. We do not know the exact ages of adolescents, but variation in body size suggests that some of this variation was age-related. Several of the smallest adolescents were among the least frequent participants (e.g. WY, BR, RI in Fig. 4), while most larger ones (e.g. GR, MT) went on relatively many patrols. However, DX and CR, who patrolled most often $(N=28)$ and who actually participated in more patrols than all but four adults, were medium-sized, and GE, a relatively small male, participated in the fourth-highest number of patrols $(N=21)$. Our reliable data on the amount of time that adolescents spent in parties with adult males do not cover the entire study period, but we had the strong impression that these three males and $\mathrm{MT}(N=23$ patrols $)$ associated with medium-sized to large parties of adults most often among adolescents.

For adolescent males also, variation in patrol frequency was significantly and positively correlated with the proportion of copulations obtained with

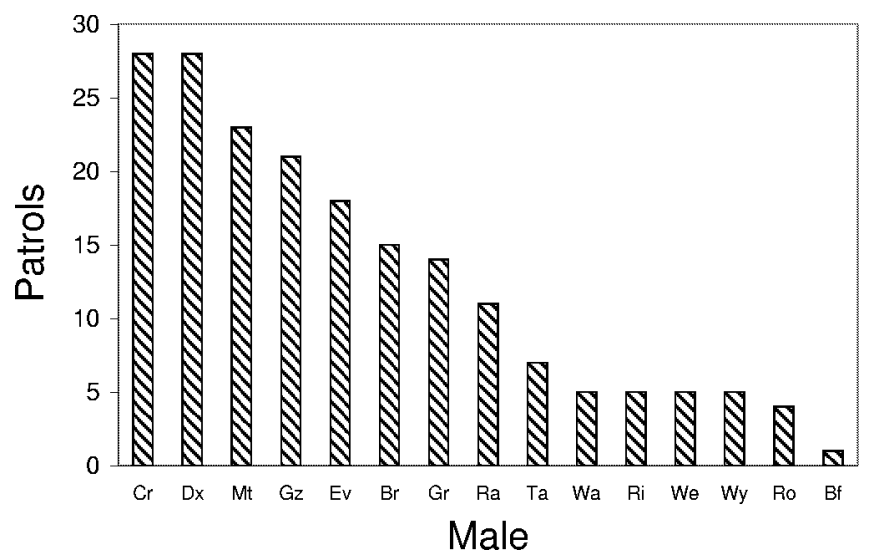

Fig. 4. Number of patrols in which adolescent males participated. Males are ordered by patrol frequency, not by rank or age. 
parous adult females $\left(F_{1,13}=37.30, r^{2}=0.72, p<0.0001\right)$. Considering only parous adults, rather than all cycling females, probably gives a better measure of adolescent competitive ability, because adult males are more likely to try to prevent them from mating with parous adults than with nulliparous females. In fact, adolescents obtained more copulations with adolescent and nulliparous adult females than with parous adults, but their shares of copulations with these two classes of females were highly correlated $\left(r^{2}=0.66, p=0.0001\right)$. The relationship of patrol frequency to mating success is almost identical if nulliparous females are included $\left(F_{1,13}=35.80\right.$, $\left.r^{2}=0.71, p<0.0001\right)$.

Only seven adolescent males made red colobus kills during our observations of hunts. These included six of the seven adolescents who patrolled most often and who were all large or medium-sized (CR, DX, MT, EV, BR, GR; Fig. 4), plus one medium-sized male who patrolled infrequently (TA; Fig. 4). GZ, a small adolescent who often patrolled (Fig. 4) and who was often present at hunts, did not capture any monkeys. Most other adolescents who did not capture monkeys were also small.

\section{Discussion}

Boundary patrols at Ngogo

The Ngogo chimpanzee community has hostile relations with its neighbors. This is evident from frequent boundary patrols, from flights, attacks, and chases when parties from different communities meet, and from infanticides during patrols (Watts \& Mitani, 2000). It is consistent with observations of intergroup aggression at Kanyawara, also in Kibale (Wrangham \& Peterson, 1996; Wrangham, 1999), and at Tai (Boesch \& Boesch, 2000), Mahale (Nishida et al., 1985), and Gombe (Goodall et al., 1979; Goodall, 1986). As we noted elsewhere (Watts \& Mitani, 2000; cf. Wrangham, 1999), our observations contradict Power's (1991) assertion that chimpanzees are 'egalitarian.' Power based her argument largely on Ghiglieri's (1984) data from Ngogo, but the chimpanzees were not well enough habituated during his study for observers to have been able to follow them on boundary patrols. Ghiglieri did not see hunts at Ngogo, either, but we now know that the chimpanzees there hunt often and with unusually high success (Mitani \& Watts, 1999; Watts \& Mitani, in press a, b). We have not seen fatal attacks 
on weaned individuals in inter-community aggression, but the deaths of an adult and an adolescent male in intergroup aggression elsewhere in Kibale (Wrangham \& Peterson, 1996; Wrangham, 1999) make us suspect that these occur at Ngogo.

Patrols were much more common at Ngogo than at Tai (Boesch \& Boesch, 2000) and Gombe (Goodall, 1986), and patrol party size was much larger. These facts were presumably related. Males in small parties are vulnerable to potentially lethal attack (Goodall et al., 1979; Goodall, 1986; Wrangham, 1999), and Tai data show that males in small communities have little inclination to risk patrolling or meeting intruders (Boesch \& Boesch, 2000). Because so many males are present at Ngogo, occasions when enough are together to make the risks of a patrol small are almost certainly more common than in smaller communities. Comparisons to Tai and Gombe suggest that variation in the number of males per community influences variation in patrol rate. Patrols can occur more often in a large community than a small one even if individual males in the large community do not patrol more often than males in the small one. Whether individuals in communities with many males are also more inclined to patrol is unclear from the present comparative sample.

The balance of power between communities and the level of intruder pressure also should influence patrol frequency because they influence the costs and benefits of territorial defense (Williams, 1999) and of attempts at territorial expansion. For example, lionesses in Ngorongoro crater are quicker to respond to simulated territorial intrusions than those in the Serengeti and approach regardless of the odds; population density and competition for territories are higher in the Crater (Heinsohn, 1997). The uneven distribution of patrols around the perimeter of the Ngogo community's range suggests that they faced varying levels of competition from neighboring communities. They might have been strong relative to the northern community, the possible home of both infanticide victims (Watts \& Mitani, 2000), but did not have a great advantage over the Kanyanchu community. Balance-of-power effects should become clearer as we gain more information about neighboring communities.

\section{Individual variation in patrolling}

Some males at Ngogo patrolled particularly often, others infrequently. This was partly an age effect, and patrol effort may generally show an inverted$\mathrm{U}$ shaped relationship to age that mirrors fighting ability: low among young 
adolescents, higher for older adolescents, higher for young and prime age adults, then lower for old males. Small adult males and males with injuries that cause permanent impairment (e.g. ST in Fig. 2) also have relatively low fighting ability and may patrol relatively infrequently, independently of age. However, adolescents who patrolled most often were not necessarily among the largest and, presumably, oldest, nor did age and size differences and degree of impairment explain all variation among adults. For example, BS, OR, and GA (first seen as adolescents) are about the same age and size, but BS patrolled almost twice as often as GA and considerably more often than OR (Fig. 2). He was also the most gregarious of these three males (Watts \& Mitani, unpubl. data).

Variation in male patrol frequency, although significant, did not necessarily show that some males cheated. Instead, the positive relationship between mating success and patrol frequency is consistent with the hypothesis that the unequal distribution of patrolling effort among adult males partly reflected asymmetric distribution of benefits. Wrangham (1999) suggested that the benefits of making raids on neighboring communities increase so sharply with increasing party size that it pays individuals to join patrols for selfish reasons. However, this may not be so at Ngogo, where a patrol party that includes only a fraction of the community's males can still easily have overwhelming superiority over opponents. This would be especially likely if diminishing marginal returns of raiding means that males who are relatively poor competitors receive relatively little benefit regardless of their effort. Like male dunnocks that calibrate parental effort to reflect variation in paternity probability (Davies et al., 1992), male chimpanzees may calibrate patrolling effort to reflect variation in expected reproductive benefits. As at other chimpanzee research sites, females at Ngogo mate with multiple males (Watts, 1998, unpubl. data), but the probability of gaining fertilizations probably increases with mating success. Many males have consistently had relatively high or low mating success throughout our observations at Ngogo (Watts, 1998, unpubl. data). Increased safety resulting from successful attacks on neighbors is a common good (Wrangham, 1999). Individual fertilizations are not, and males presumably do not get equal numbers of fertilizations. Males with relatively many offspring and/or with good prospects for siring offspring should have more to gain from protecting infants, improving female foraging efficiency, and attracting females than males with few offspring and poor prospects. They should be more willing to invest time and 
energy in patrolling and to take associated risks. Patrolling is probably partly parental effort, both directly (if it improves offspring safety) and indirectly (if it increases rates of successful reproduction by females). Williams (1999) reached a similar conclusion in her analysis of long-term data from Gombe, which show that increased territory size due to success in intergroup aggression led to higher female reproductive rates. Williams (ibid.) concluded that patrolling was not mating effort, because males often attacked females and rarely mated with their victims subsequent to those attacks. However, territory expansion can increase the number of mates available to males (Nishida et al., 1985), so patrolling could sometimes also represent mating effort.

Males sometimes refrained from participating in patrols that they had the opportunity to join. Individual variation in the tendency to refrain was not great, but some males were especially likely to join patrols, and joiners also generally went on patrols relatively often. Male EL, in particular, often initiated and led patrols and re-started movement after patrol members had stopped to listen. Two results support the hypothesis that male willingness to join patrols also reflected current and expected future reproductive gains. First, rank-independent mating success was positively correlated with the percentage of patrol opportunities taken. Certain males, not all high ranking, seem particularly persistent and assertive at seeking matings. Several of these who also rarely forsook patrol opportunities have risen considerably in rank during the time of observations reported here or since (e.g. $\mathrm{HO}$ and BE; Fig. 3, unpubl. data). Second, variation in patrol frequency was also positively correlated with variation in mating success for adolescent males. Their likelihood of siring offspring was presumably low because their share of copulations with adult females was always low. However, assertiveness in mating (often in the face of aggression from adult males) and in patrolling might be characteristics of ambitious adolescents who will eventually attain high rank, and frequent participation in patrols may help them develop alliances with adult males that facilitate this goal.

The presence of many males can increase the chances that individuals cheat when they face collective action problems (Nunn, 2000). However, the consequences of cheating may be more severe in communities with fewer males, in which the risks associated with patrolling may be too great, and/or the chance of achieving overwhelming superiority too low, unless most or all males participate. If males only try to start patrols when most or all are together, they could have sufficient knowledge of each other's participation 
to punish cheaters (Boehm, 1999), although no clear evidence of punishment exists (Wrangham, 1999).

Cheating may also be more of an issue when males face direct threats, and when failure of some to cooperate could lead to the deaths of others, thus weakening the community's position in competition with neighbors (Wrangham, 1999). Again, the likelihood that cheating could have such severe consequences presumably varies inversely with the number of males per community. Playback experiments with male lions in the Serengeti showed that individual willingness to respond to direct threats from extrapride males did not vary, presumably because the costs that failure to cooperate can impose on cheaters is too high (Grinnell et al., 1995). Similar experiments with Serengeti females showed complicated variation, with some females consistently leading approaches towards perceived threats and others consistently lagging (Heinsohn \& Packer, 1995). We cannot address the issue of direct threats, because patrols were not obviously responses to them. In comparison to male lions facing the choice of whether to join coalition partners against outside males, the cost per opportunity is probably much less for chimpanzee males deciding whether to join others on patrols during which they may, or may not, encounter direct risks. Groups of male chimpanzees do not try to invade neighboring communities and evict resident males in lion-like fashion, although gradual aggressive male replacement is possible (Goodall et al., 1979; Nishida et al., 1985). Also, male chimpanzees usually exercise great caution when opportunities for intergroup aggression arise. Individuals may often be able to refrain from patrols without seriously penalizing others who participate, especially when the community contains many males and participants can still form large parties.

The dynamics of social relationships probably also influence individual decisions about patrol participation. Long-time alpha male MW put surprisingly low effort into patrolling, especially given that he had the highest mating success among males (Watts, 1998, unpubl. data). Most patrols that we observed occurred during a period when male LO reversed rank with several other top-ranking males and then made a prolonged and successful challenge of MW and replaced him as alpha. As his hold on the alpha position became tenuous, MW might have refrained from patrols to avoid situations in which he could have faced challenges. BA, who had been MW's main ally for several years, refrained from several patrols that LO joined after LO had become alpha; BA seemed not to want to associate with LO. 


\section{Patrolling and male-male bonds}

Male bonding is not a necessary prerequisite for coalitionary lethal intergroup aggression in mammals, but presumably underlies its occurrence in chimpanzees (Wrangham, 1999). Individual decisions to participate in activities that can lead to lethal intergroup aggression reflected the quality of social bonds between males at Ngogo. Males patrolled most often with others with whom they often groomed and with whom they cooperated in other contexts by forming coalitions. Males may generally be confident that allies (regular coalition partners) and others with whom they often groom will share the risks associated with encounters during patrols. An earlier analysis that included a small part of the patrol sample included here produced similar results and also indicated that potential maternal relatedness did not influence joint participation in patrols (Mitani et al., 2000). Alliance formation in wild chimpanzees does not necessarily depend on maternal relatedness (ibid.; de Waal, 1982; Goldberg \& Wrangham, 1997). Instead, as in baboons (Smuts, 1985; Smuts \& Watanabe, 1990; Noë, 1992; Noë \& Sluijter, 1995), it depends crucially on familiarity, trust, and considerations of combined agonistic power and of leverage (de Waal, 1982; Nishida 1983; Goodall, 1986; Nishida \& Hosaka, 1996). At Ngogo, males are probably most likely to patrol when many are together near a boundary, or at one of several 'jumping-off points' from which they move quickly to boundaries, and those present trust each other to assume any risks.

If costly signaling theory (Zahavi, 1975; Grafen, 1990) applies to boundary patrolling at Ngogo, it may be most relevant to male bonding. Willingness to patrol may convey reliable information about competitive ability, health, and vigor, but this probably has little direct effect on male mating success because females rarely accompany males and thus do not receive the information. In communities where females go on patrols more often, they may use participation by males as signals with which to evaluate mate quality. However, males who patrol can get this information - although only by paying the same costs and taking the same risks as signallers - and could use it to help assess the value of signalers as potential allies (Smith \& Bliege Bird, 2000). Patrollers could accrue benefits if patrolling induces other males to form effective alliance with them. Thus the connections of joint patrolling to coalition formation and to grooming could go both ways. One male could indicate to a second that he could be trusted on a patrol by forming coalitions 
with the second; correspondingly, he could take the second male's frequent presence on patrols as one indication that the second would be a valuable ally.

\section{Boundary patrols and hunting}

Males who hunted often and who were successful at killing monkeys also were particularly likely to participate in boundary patrols. Wrangham (1999) summarizes the many resemblances between behavior during group hunts and that during coalitionary attacks. For example, males show signs of physiological arousal, like piloerection, in both contexts. At Ngogo, males also often go on prolonged, silent searches for red colobus monkeys that resemble boundary patrols (Mitani \& Watts, 1999; Mitani \& Watts, in press). Our data do not resolve the question of whether monkey hunting by chimpanzees is derived from lethal intergroup aggression (Eibl-Eibesfeldt, 1979; Goodall, 1986; van Hooff, 1990; Wrangham, 1999). However, they show that males highly motivated to pursue monkeys - an activity that demands agility and that involves risk taking and coordination of one's own behavior with that of others - are also highly inclined to take the risks involved in pursuing other chimpanzees. Prey pursuit provides public information about such inclinations and about physical skills and thus also qualifies as a candidate for costly signaling, especially when males share meat from their captures. This information is often available to females as well as males. Males could use the behavior of other males during hunts to assess their value as patrol partners.

\section{Ngogo as a special case}

Our observations strengthen the argument that coalitionary intergroup aggression is typical behavior for chimpanzee males (Wrangham \& Peterson, 1996; Wrangham, 1999). Some aspects of intergroup antagonism at Ngogo may present males with collective action problems, but this may not be the case for boundary patrols. Data on mating success indicate instead that variation in current and future reproductive success probably accounted for much of the variation in the effort that males put into patrolling. We also found that males who often took part in red colobus hunts and who often captured prey put high effort into patrolling. Males patrolled often with others with whom they often groomed, with whom they formed coalitions, and with whom they 
often hunted. Thus, variation in the quality of male bonds seems to contribute to individual decisions to go on patrols, and whether males often patrol together may influence the quality of their social bond. Almost certainly, we were able to show these relationships because the large number of males at Ngogo means that average patrol size can be high even if some males patrol infrequently. The distribution of any reproductive benefits from patrolling is probably skewed. For an individual with low expected benefits, the costs of refraining from any given patrol are probably also low. Similar relationships may not hold in chimpanzee communities with fewer males, because achieving a sufficient imbalance of power may only be possible when patrols consist of most or all males.

\section{References}

Boehm, C. (1999). Hierarchy in the forest: the evolution of egalitarian behavior. - Harvard University Press, Cambridge, Mass.

Boesch, C. (1994). Cooperative hunting in wild chimpanzees. - Anim. Behav. 48, p. 653667.

— — \& Boesch, H. (1989). Hunting behavior of wild chimpanzees in the Tai National Park. - Am. J. Phys. Anthropol. 78, p. 547-573.

- - \& - - (2000). The chimpanzees of the Tai forest. — Oxford University Press, Oxford.

Caro, T.M. \& Collins, D.A. (1986). Male cheetahs of the Serengeti. — Natl. Geogr. Res. 2, p. 75-86.

Davies, N.B., Hatchwell, B.J., Robson, T. \& Burke, T. (1992). Paternity and parental effort in dunnocks (Prunella modularis): how good are male chick-feeding rules? - Anim. Behav. 43, p. 729-745.

Eibl-Eibesfeldt, I. (1979). The biology of war and peace. — Viking, New York.

Ghiglieri, M. (1984). The chimpanzees of the Kibale forest. - Columbia University Press, New York.

Goldberg, T.L. \& Wrangham, R.W. (1997). Genetic correlates of social behavior in wild chimpanzees: evidence from mitochondrial DNA. - Anim. Behav. 54, p. 559-570.

Goodall, J. (1977). Infant-killing and cannibalism in free-living chimpanzees. - Folia Primatol. 28, p. 259-282.

- - (1986). The chimpanzees of Gombe. - Harvard Univ. Press, Cambridge, Massachusetts.

_- B Bandora, A., Bergmann, E., Busse, C., Matama, H. \& Russ, D. (1979). Intercommunity interactions in the population of chimpanzees in the Gombe National Park. - In: The great apes (D.A. Hamburg \& E.R. McKown, eds). Benjamin Cummings, Menlo Park, p. 13-54.

Grafen, A. (1990). Biological signals as handicaps. - J. theor. Biol. 144, p. 517-546.

Grinnell, J., Packer, C. \& Pusey, A.E. (1995). Cooperation in male lions: kinship, reciprocity, or mutualism? - Anim. Behav. 49, p. 95-105. 
Heinsohn, R. (1997). Group territoriality in two populations of African lions. - Anim. Behav. 53, p. 1143-1147.

— — \& Packer, C. (1995). Complex cooperative strategies in group-territorial African lions. - Science 269, p. 1260-1263.

Hemelrijk, C.K. (1990a). Models of, and tests for, reciprocity, unidirectionality, and other social interaction patterns at group level. - Anim. Behav. 39, p. 1023-1029.

- _ (1990b). A matrix partial correlation test used in investigations of reciprocity and other social interaction patterns at a group level. - J. theor. Biol. 143, p. 405-420.

van Hooff, J.A.R.A.M. (1990). Intergroup competition and conflict in animals and man. In: Sociobiology and conflict: evolutionary perspectives on cooperation, competition, violence, and warfare (J.M.G. van der Dennen \& V.S.E. Falger, eds). Chapman and Hall, London, p. 23-54.

Keeley, L.H. (1996). War before civilization: the myth of the peaceful savage. - Oxford University Press, Oxford.

Kruuk, H. (1972). The spotted hyena. - University of Chicago Press, Chicago.

Mech, L.D., Adams, L.G., Meier, T.J., Burch, J.W. \& Dale, T.W. (1998). The wolves of Denali. - University of Minnesota Press, Minneapolis.

Manson, J.H. \& Wrangham, R.W. (1991). Intergroup aggression in chimpanzees and humans. - Curr. Anthro. 32, p. 369-390.

Mitani, J., Hunley, K.L. \& Murdoch, M.E. (1999). Geographic variation in the calls of wild chimpanzees: a reassessment. - Amer. J. Primatol. 47, p. 133-151.

— - Merriwether, D.A. \& Zhang, C. (2000). Male affiliation, cooperation, and kinship in wild chimpanzees. - Anim. Behav. 59, p. 885-893.

— — \& Watts, D.P. (1999). Demographic influences on the hunting behavior of chimpanzees. - Amer. J. Phys. Anthropol. 109, p. 439-454.

— — \& - - (in press). Why do chimpanzees hunt and share meat? — Anim. Behav.

Nishida, T. (1968). The social group of wild chimpanzees in the Mahale Mountains. Primates 9, p. 167-224.

- - (1983). Alpha status and agonistic alliance in wild chimpanzees (Pan troglodytes schweifurthii). - Primates 24, p. 318-336.

— - Hiraiwa-Hasegawa, M. \& Takahata, Y. (1985). Group extinction and female transfer in wild chimpanzees in the Mahale National Park, Tanzania. - Z. Tierpsychol. 67, p. 284-301.

—— \& Hosaka, K. (1996). Coalition strategies among adult male chimpanzees of the Mahale Mountains, Tanzania. - In: Great ape societies (W.A. McGrew, L.A. Marchant \& T. Nishida, eds). Cambridge University Press, Cambridge, p. 114-134.

Noë, R. (1992). Alliance formation among male baboons: shopping for profitable partners.

- In: Coalitions and alliances in humans and other animals (A.H. Harcourt \& F.B.M. de Waal, eds). Cambridge University Press, Cambridge, p. 285-321.

— — \& Sluijter, A.A. (1995). Which adult male savanna baboons form coalitions? — Int. J. Primatol. 16, p. 77-106.

Nunn, C.L. (2000). Collective benefits, free riders, and male extra-group conflict. - In: The socioecology of male primates (P. Kappeler, ed.). Cambridge University Press, Cambridge, p. 192-204.

Packer, C. Scheel, D. \& Pusey, A.E. (1990). Why lions form groups: food is not enough. Amer. Nat. 136, p. 1-19. 
Pepper, J., Mitani, J.C. \& Watts, D.P. (1999). General gregariousness and specific partner preference among wild chimpanzees. - Int. J. Primatol. 20, p. 613-632.

Power, M. (1991). The egalitarians: human and chimpanzee. - Cambridge University Press, Cambridge.

Pusey, A.E. (1979). Inter-community transfer of chimpanzees in Gombe National Park. In: The great apes (D.A. Hamburg \& E.R. McCown, eds). Benjamin-Cummings, Menlo Park, California, p. 465-479.

Smith, E.A. \& Bliege Bird, R. (2000). Turtle hunting and tombstone opening: public generosity as costly signalling. - Evol. Human Behav. 21, p. 245-261.

Smuts, B.B. (1985). Sex and friendship in baboons. - Aldine, Chicago.

— — \& Watanabe, J. (1990). Social relationships and ritualized greetings in adult male baboons (Papio cynocephalus anubis). - Int. J. Primatol. 11, p. 147-172.

Stanford, C.B. (1998). Chimpanzee and red colobus: the ecology of predator and prey. Harvard University Press, Cambridge.

— —, Wallis, J., Matama, H. \& Goodall, J. (1994). Patterns of predation by chimpanzees on red colobus monkeys in Gombe National Park, 1982-1991._ Amer. J. Phys. Anthropol. 94, p. 213-228.

Struhsaker, T.T. (1997). Ecology of an African rain forest. - University Presses of Florida, Gainesville, Florida.

de Waal, F.B.M. (1982). Chimpanzee politics. - Johns Hopkins University Press, Baltimore.

Watts, D.P. (1998). Coalitionary mate guarding by male chimpanzees at Ngogo, Kibale National Park, Uganda. - Behav. Ecol. Sociobiol. 44, p. 43-55.

- - (2000a). Grooming between male chimpanzees at Ngogo, Kibale National Park, Uganda. I. Partner number and diversity and reciprocity. - Int. J. Primatol. 21, p. 189210 .

- - (2000b). Grooming between male chimpanzees at Ngogo, Kibale National Park, Uganda. II. Male rank and priority of access to partners. - Int. J. Primatol. 21, p. 211238.

— - \& Mitani, J.C. (2000). Infanticide and cannibalism by male chimpanzees at Ngogo, Kibale National Park, Uganda. — Primates 41, p. 357-364.

— — \& Mitani, J.C. (in press, a). Hunting by chimpanzees at Ngogo, Kibale National Park, Uganda. - Int. J. Primatol.

— — \& Mitani, J.C. (in press, b). Hunting and meat sharing by chimpanzees at Ngogo, Kibale National Park, Uganda. - In: Behavioral diversity in chimpanzees and bonobos (G. Hohmann \& C. Boesch, eds). Cambridge University Press, Cambridge.

Williams, J.M. (1999). Female strategies and the reasons for territoriality in chimpanzees: lessons from three decades of research at Gombe. - Unpubl. PhD thesis, University of Minnesota.

Wrangham, R.W. (1979). On the evolution of ape social systems. - Social Sci. Information 18 , p. 335-368.

- - (1999). Evolution of coalitionary killing. — Yrbk. Phys. Anthro. 42, p. 1-30.

— - (2000). Why are male chimpanzees more gregarious than mothers? A scramble competition hypothesis. - In: The socioecology of primate males (P.K. Kappeler, ed.). Cambridge University Press, Cambridge, p. 248-258. 
— — \& Peterson, D. (1996). Demonic males. — Houghton Mifflin, New York.

Zahavi, A. (1975). Mate selection: a selection for a handicap. — J. theor. Biol. 53, p. 205-214. 